Cytogenet Genome Res 1983;35:160

\title{
Identification of participants
}

Fourth Basel Colloquium on Mammalian Sex Chromosomes in Differentiation and Development. March 30 to April 1, 1967. Basel, Switzerland. One of the main areas of the discussions at this colloquium

was centered on the then recent hypothetical proposals of X-inactivation of Drs. Lyon, Griineberg, and Russell (Nos. 11, 12, and 13 in photograph). The participants were:

M. Fraccaro

H.P. Klinger

P.E. Polani

U. Mittwoch

R.G. Edwards

A. Motulsky

M. Siniscalco

A. Franceschetti

J.H. Edwards

J. Weiss

M.F. Lyon

H. Griineberg

L.B. Russell

R. Matthey

W. Schmid

1 R.A. Beatty

1 P. A. Jacobs

31. G. Debrunner

1 H.G. Schwarzacher

32. S. Ohno

1 M.A. Ferguson-Smith

33. E. Witschi

34. C.E. Ford

2 A. Kallenberger

35. O.J. Miller

2 G.M. Jagiello

36. R.G. Davidson

2 E. Bergemann

37. F. Giannelli

2 K. Mikamo

2 L. De Carli

38. J.L. Hamerton.

2 J.L. German

2 M. Tolksdorf

2 G. Wolf-Heidegger

2 L. Tiepolo

2 U. Wolf

3 B.M. Cattanach

E. Ffadorn, J.E. Lindsten, and $\mathrm{V}$. Monesi were also present at the colloquium but are not in the photograph. 